Date: May 26, 1992

TTTLE: Chemistry of Coal-Related Microparticles

PIs: $\quad$ Professors E. James Davis and Barbara Krieger-Brockett

STUDENTS: Theresa M. A.len, Ph.D. Candidate in Chemical Engineering

Scot D. Rassat, Ph.D. Candidate in Chemical Engineering

DOE/FC/89790--10

DE92 018452

INSTITUTION: Department of Chemical Engineering, BF-10

University of Washington

Seattle, WA 98195

(206) 543-2250 and FAX 2065433778

GRANT NO:: DE-FG22-89PC89790

PERIOD OF PERFORMANCE: 03/01/92-5/31/92

$$
\text { intor } 64
$$

\title{
BACKGROUND
}

This research project involves the study of coal macerals and sorbent microparticles used to remove $\mathrm{SO}_{2}$ and/or $\mathrm{H}_{2} \mathrm{~S}$ from process streams. To measure reaction rates a charged single microparticle will be held electrodynamically in one or more laser bearns by superposed ac and dc electrical fields. The use of the electrodynamic balance for microparticle studies was pioneered by one of the principal investigators. One of the laser beams is used for light-scattering measurements to determine the particle size and to provide the excitation source for obtaining Raman spectra to chemically characterize the particle. The other beam, an infrared beam, is used to heat the particle electromagnetically. The first year of the research was devoted to preliminary experimental work and design studies. Although components and techniques must still be developed, experimental measurements on single macerals are now being done.

\section{WORK COMPLETED}

During this quarter of the project, graduate student Scot Rassat continued his work on the measurement of chemical reaction rates between a calcium oxide particle and a humid stream of nitrogen containing sulfur dioxide. Mathermatical modeling of the process has also been carried out. Microparticle Raman measurements indicate that at low temperatures the reaction involves two steps (i) the takeup of water and subsequent reaction to form calcium hydroxide, and (ii) the reaction of sulfur dioxide with calcium hydroxide to form the hemihydrate of calcium sufite. The reactions are

and

$$
\mathrm{CaO}+\mathrm{H}_{2} \mathrm{O} \rightarrow \mathrm{Ca}(\mathrm{OH})_{2}
$$

$$
\mathrm{Ca}(\mathrm{OH})_{2}+\mathrm{SO}_{2} \rightarrow \mathrm{CaSO}_{3} \bullet \frac{1}{2} \mathrm{H}_{2} \mathrm{O}+\frac{1}{2} \mathrm{H}_{2} \mathrm{O}
$$

Raman spectra obtained during the reaction are presented in Figures 1 and 2. Figure 1 shows the formation of the $\mathrm{O}-\mathrm{H}$ bond of calcium hydroxide at a Raman shift of $3700 \mathrm{~cm}^{-1}$, and Figure 2 shows the formation of the $\mathrm{S}-\mathrm{O}$ bond in $\mathrm{SO}_{3}{ }^{-}$as the reaction proceeds. 
Gravimetric data obtained simultaneously with the spectroscopic data indicate that the particle mass slowly increased by $45 \%$ when only water was present in the gas phase. This exceeds the stoichiometric amount corresponding to complete conversion to calcium hydroxide. Figure 3 demonstrates this point. When sulfur dioxide was present in the gas stream the mass increase approached $100 \%$, but the reaction did not proceed to completion. This is also shown in Figure 3. Mathematical modeling of the process suggests that pore-plugging occurred to limit the utilization of the sorbent. The results of the calcium oxide reaction experiments will appear in the latest issue of the Journal of Aerosol Science.

Theresa Allen completed the design and installation of the infrared laser heating system and infrared detectors for particle temperature measurement. The Class IV infrared laser system requires careful design, for the $30 \mathrm{~W}$ laser beam represents a danger to the users. The beam has been enclosed in ceramic tubes to protect the researchers from accident. The apparatus is currently being tested at low power.

\section{PLANS FOR THE NEXT QUARTER}

Theresa Allen will complete experimental studies of microparticle heating, and Scot Rassat will use her infrared heating system for measurements of maceral devolatilization and desulfurization kinetics at elevated temperatures. Two methods will be applied to measure the particle temperature (i) two-color optical pyrometry and (ii) measurements of the Stokes and antiStokes Raman spectra. The infrared detectors recently installed will be used for optical pyrometry, and the Raman spectrorneter will be used to determine the ratio of the Stokes and anti-Stokes signals. The latter is highly sensitive to particle temperature at elevated remperatures.

\section{DISCLAIMER}

\footnotetext{
This report was prepared as an account of work sponsored by an agency of the United States Government. Neither the United States Grovernment nor any agency thereof, nor any of their employees, makes any warranty, express or implied, or assumes any legal liability or responsiprocess disclosed, or represents that, or usefulness of any information, apparatus, product, or ence herein to any specific manufacturer, or otherwisc ommercial product, process, or service by trade name, trademark, manufacturer, or otherwise does not necessarily constitute or imply its endorsement, recomand opinions of aung by the United States Government or any agency thereof. The views United States Government
} 


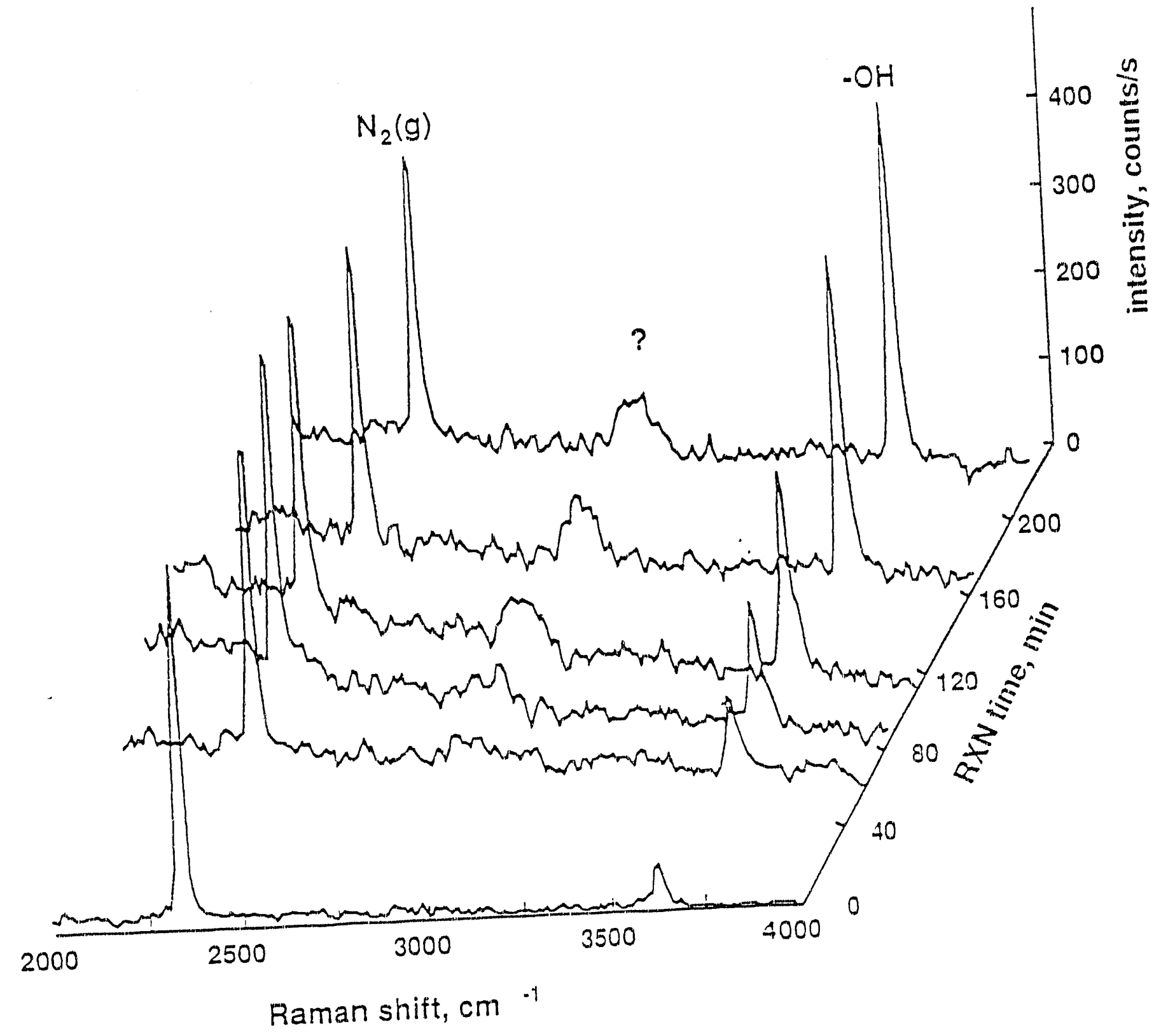

Figure 1 Raman spectra during the reaction of a single $\mathrm{CaO}$ microparticle with water vapor in ritrogen 


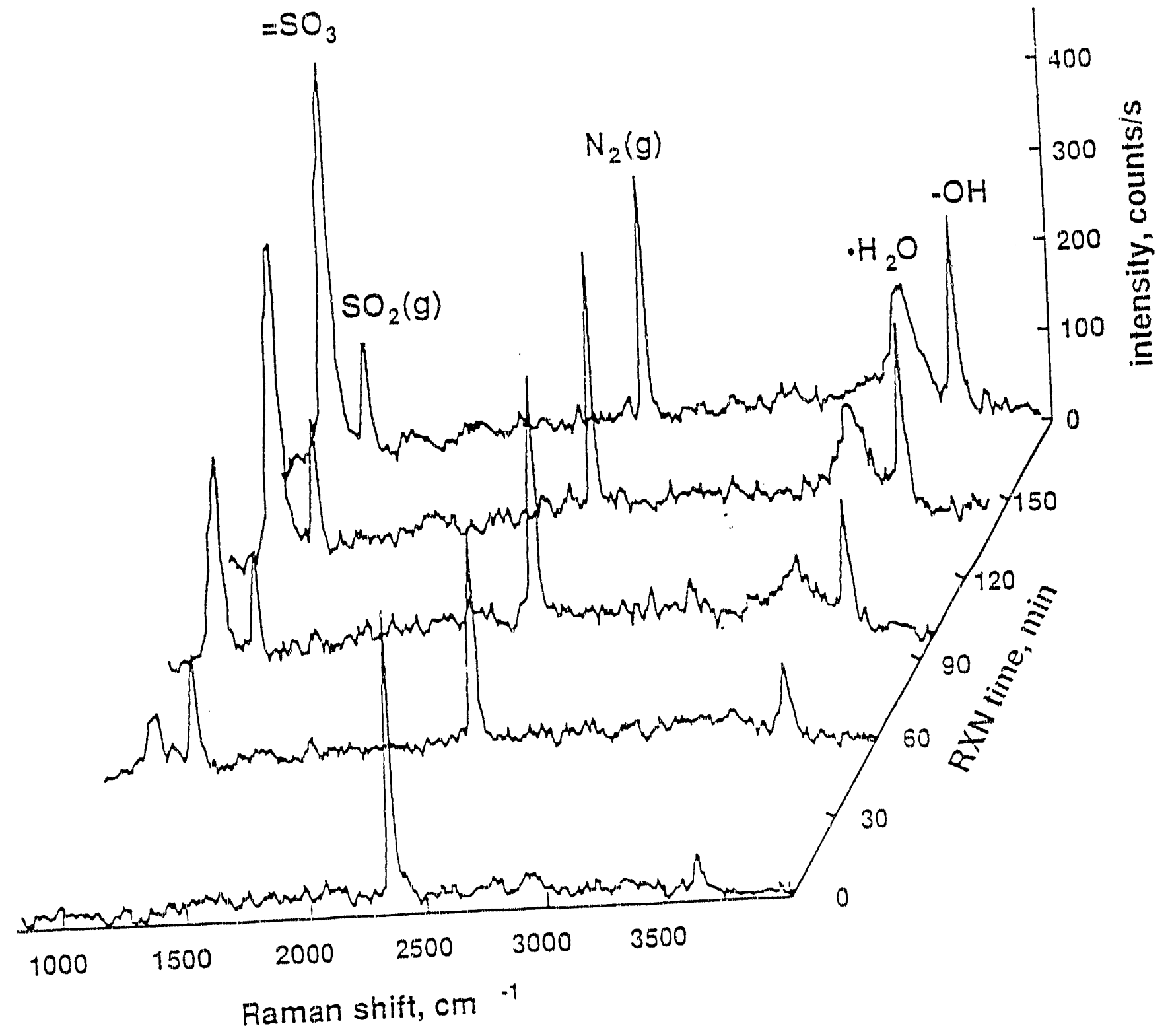

Figure 2 Raman spectra during the reaction of a single $\mathrm{CaO}$ microparticle with water vapor and sulfur dioxide in nitrogen 


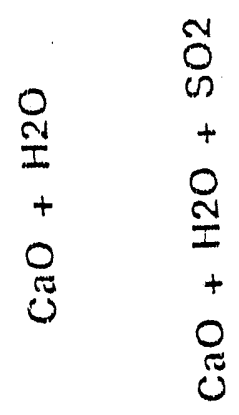

-

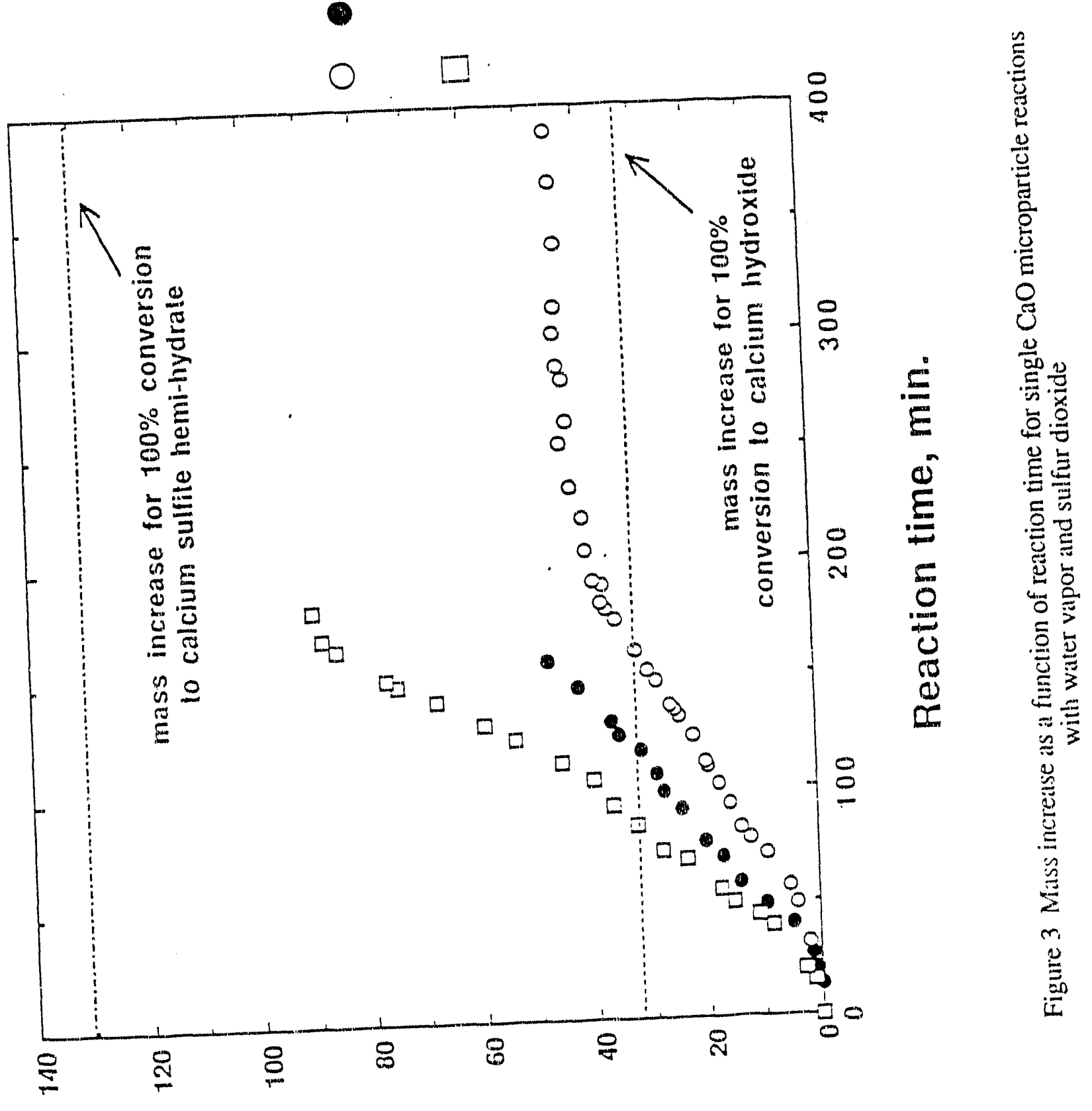



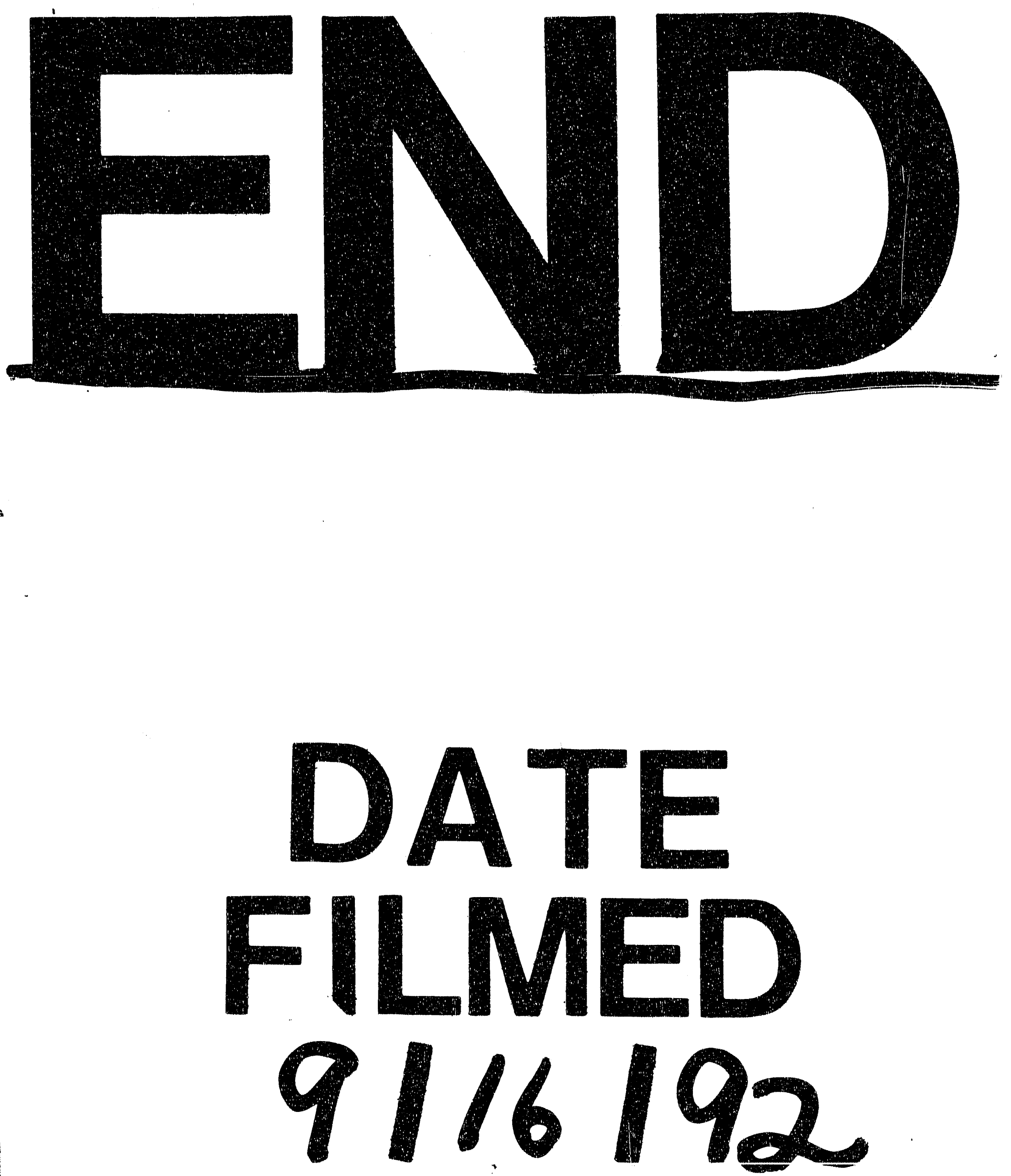


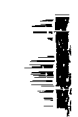

